\title{
Feasibility of Intranasal Dexmedetomidine in Treatment of Postoperative Restlessness, Agitation, and Pain in Geriatric Orthopedic Patients
}

\author{
Panu Uusalo ${ }^{1,2}$ (D) . Suvi-Maria Seppänen ${ }^{1,2} \cdot$ Mikko J. Järvisalo $^{1,2}$
}

Accepted: 19 February 2021 / Published online: 16 March 2021

(c) The Author(s) 2021

\begin{abstract}
Objective The aim of this study was to report preliminary data on the use of intranasal dexmedetomidine to treat postoperative restlessness, agitation, and pain in 23 patients aged $>70$ years and undergoing orthopedic surgery.

Background Postoperative agitation and delirium are common among older adult patients undergoing orthopedic surgery. Most preparations used to treat agitation and delirium carry a risk for adverse events such as respiratory failure. Moreover, mere opioid therapy may be insufficient in treatment of pain. Dexmedetomidine, an $\alpha 2$-adrenoreceptor agonist with sedative and analgesic properties, has been shown to reduce opioid requirement and reduce postoperative delirium in older adults. Methods We studied the use of post-operative intranasal dexmedetomidine in a retrospective study cohort of geriatric patients undergoing orthopedic surgery. Primary outcomes included alterations in heart rate (HR), mean arterial pressure (MAP), respiratory rate (RR), peripheral oxygen saturation (SpO2), Modified Richmond Agitation and Sedation Score (mRASS), and opioid consumption following dexmedetomidine administration.

Results We identified 23 patients with a mean (SD) age of 79.9 (7.5) years who received dexmedetomidine $100 \mu \mathrm{g}$ intranasally postoperatively. After dexmedetomidine administration, HR decreased by 10.4 (3.7) beats/min (95\% CI 2.9-17.8; $p=0.004)$ and MAP by $16.2(4.4) \mathrm{mmHg}(95 \% \mathrm{CI} 7.3-25.1 ; p<0.001)$. HR decrease was significant at $2 \mathrm{~h}$ and MAP decrease at 1,2 , and $3 \mathrm{~h}$ following dexmedetomidine administration. Dexmedetomidine administration was associated with significant reductions in opioid consumption $(p<0.001)$ and mRASS score $(p<0.001) . \mathrm{SpO}_{2}$ and $\mathrm{RR}$ remained unchanged. Conclusions These preliminary findings suggest that intranasal dexmedetomidine reduces opioid consumption without causing respiratory depression and may be used to treat postoperative restlessness, agitation, and pain in geriatric patients. However, hemodynamic effects of dexmedetomidine may require close observation for 3 hours following administration in older adult patients.
\end{abstract}

Panu Uusalo

pijuus@utu.fi

Suvi-Maria Seppänen

suvi-maria.seppanen@tyks.fi

Mikko J. Järvisalo

mikko.jarvisalo@tyks.fi

1 Perioperative Services, Intensive Care and Pain Medicine, Turku University Hospital, Turku, Finland

\section{Key Points}

Intravenous dexmedetomidine has been shown to have anti-delirium and analgesic-sparing effects in older adults undergoing surgery.

Administration of intranasal dexmedetomidine is effective for the treatment of postoperative restlessness, agitation, and pain in geriatric patients undergoing orthopedic surgery.

Hemodynamic changes related to intranasal dexmedetomidine require observation for 3 hours following administration in older adult patients.

2 Department of Anaesthesiology and Intensive Care, University of Turku, Kiinamyllynkatu 4-8, P.O. Box 51, 20521 Turku, Finland 


\section{Introduction}

Dexmedetomidine is a relatively new drug that acts by activating $\alpha 2$-adrenoceptors. It has been registered for intensivecare sedation and procedural sedation in adult patients. In addition to its sedative property, dexmedetomidine exerts analgesic and antiemetic effects. In comparison with other analgesic and sedative agents, dexmedetomidine has minimal effects on respiration.

There is a growing body of evidence suggesting that intraoperative use of dexmedetomidine decreases the risk and occurrence of perioperative delirium in older adults. Moreover, recent studies have suggested that intraoperative dexmedetomidine infusion is associated with lower incidence of postoperative acute kidney injury, diminished opioid consumption, and shorter extubation time and hospital stay in older adult patients [1]. It may also improve the quality of the first night's sleep following surgery [2-4].

Postoperative intravenous dexmedetomidine has been suggested to reduce the risk of delirium in surgical patients, particularly following cardiac surgery, whereas no such data are available on intranasal administration [5]. Perioperatively administered intranasal dexmedetomidine has mostly been studied in pediatric populations, and data on adult patients are scarce $[6,7]$. Intranasal dexmedetomidine exerts high bioavailability in healthy volunteers [8] but use of this administration route has not been previously studied in a postoperative setting in adult patients.

As older adult patients have a high incidence of perioperative restlessness and agitation and are prone to adverse effects of standard analgesic and sedative agents, it would be invaluable to find additional options for treating postoperative pain in this challenging patient group. Therefore, we aimed to retrospectively evaluate the usefulness of intranasal dexmedetomidine for postoperative restlessness, agitation, and pain in older adult patients undergoing orthopedic surgery at an academic medical center during a 1-year study period.

\section{Methods}

\subsection{Patient Population}

We retrospectively identified consecutive patients aged $>$ 70 years, undergoing orthopedic surgery between October 2019 and October 2020, and receiving a single dose of intranasal dexmedetomidine $100 \mu \mathrm{g}$ postoperatively for postoperative restlessness, agitation, or pain in an orthopedic postoperative care unit of a tertiary university hospital. Patients with hourly recordings of blood pressure, heart rate $(\mathrm{HR})$, respiratory rate (RR) and peripheral oxygen saturation
$\left(\mathrm{SpO}_{2}\right)$ before and at least $5 \mathrm{~h}$ following administration of intranasal dexmedetomidine were included in the study.

We excluded patients receiving other sedatives for delirium or agitation within $6 \mathrm{~h}$ prior to or after dexmedetomidine administration, patients with unstable hemodynamics and respiration, patients requiring vasoactive agents at the time of or $6 \mathrm{~h}$ prior to dexmedetomidine administration, patients with contraindications for administration of dexmedetomidine (i.e., advanced atrioventricular block [grade 2 or 3] unless paced, uncontrolled hypotension, acute cerebrovascular conditions, or prior hypersensitivity to the active substance), and patients with insufficient recordings of hemodynamic and respiratory parameters. Eligible patients were identified, and patient data were retrieved from the patient database of Turku University Orthopedic Hospital, Finland.

\subsection{Drug Administration}

Intranasal dexmedetomidine $(100 \mu \mathrm{g} / \mathrm{mL})$ was administered using a LMA MAD Nasal ${ }^{\mathrm{TM}}$ device in the surgical ward by registered nurses educated on the administration technique. The patients were kept in a semi-recumbent position, their nasal passages were cleaned and $50 \mu \mathrm{g}(0.5 \mathrm{~mL})$ doses of dexmedetomidine hydrochloride were administered to both nostrils.

\subsection{Pharmacodynamic Assessment}

We recorded HR, mean arterial pressure (MAP), $\mathrm{SpO}_{2}, \mathrm{RR}$, and fraction of inspired oxygen $\left(\mathrm{FiO}_{2}\right)$ before dexmedetomidine administration and hourly up to $5 \mathrm{~h}$ following dexmedetomidine administration. Modified Richmond Agitation and Sedation Scale (mRASS) [9] was used to assess the level of restlessness and sedation. Baseline mRASS was recorded before dexmedetomidine administration and lowest mRASS value was obtained within $4 \mathrm{~h}$ after dexmedetomidine administration. Pain was assessed by recording cumulative opioid consumption in morphine equivalent doses for 6 $\mathrm{h}$ preceding and for $6 \mathrm{~h}$ following dexmedetomidine administration, respectively.

\subsection{Statistics}

Our primary outcome measures were to evaluate the changes in MAP, $\mathrm{HR}, \mathrm{SpO}_{2}$, and RR from the baseline value within 5 $\mathrm{h}$ of dexmedetomidine dosing, cumulative opioid consumption $6 \mathrm{~h}$ before and $6 \mathrm{~h}$ after dexmedetomidine dosing, and mRASS at dexmedetomidine administration and lowest value of mRASS within the following $4 \mathrm{~h}$ of dexmedetomidine dosing. Secondary outcomes were time between surgery and dexmedetomidine administration, time to mobilization after dexmedetomidine administration, and $\mathrm{FiO}_{2}$ during dexmedetomidine administration. The Shapiro-Wilks 
test $(p>0.05)$ was used to assess normality assumptions. Student's paired $t$ tests were used to assess the change in vital signs at five different time points compared with the baseline value for normally distributed variables and SteelDwass test for skewed variables. Nominal data were tested using chi-square analysis. $p$ Value $<0.05$ (two-tailed) was considered statistically significant. When the normality assumption was not met, median difference and $90 \%$ confidence interval (CI) were calculated with bootstrap analysis. The results are expressed as mean values with standard deviations (SD), and as medians with interquartile ranges (IQR) when the normality assumption was not met. The analyses were performed with JMP Pro 13.0 for Mac (SAS Institute Inc., Cary, NC, USA).

\subsection{Adverse and Serious Adverse Events}

Bradycardia ( $\mathrm{HR}<40 / \mathrm{min}$ ), hypotension (MAP $<65 \mathrm{mmHg}$ exceeding a 1-h duration or any MAP $<60 \mathrm{mmHg}$ ), excessive sedation (mRASS $<-3$ ), hypoxia $\left(\mathrm{SpO}_{2}<92 \%\right)$, hypoventilation $(\mathrm{RR}<10 / \mathrm{min}$ or $<8 / \mathrm{min}$ if baseline $\mathrm{RR}$ was $<10 / \mathrm{min}$ ), nausea, or vomiting within $6 \mathrm{~h}$ of dexmedetomidine administration were considered as adverse events. Loss of consciousness, or need for vasopressor infusion, assisted ventilation, or intubation were considered as serious adverse events.

\section{Results}

Twenty-three consecutive eligible patients were included in the study (Supplemental Fig. 1, see Electronic Supplementary Material). Patient characteristics and demographic data are shown in Table 1. A total of 14 patients required norepinephrine therapy (median dose $0.014 \mu \mathrm{g} / \mathrm{kg} / \mathrm{h}$ [IQR $0.000-0.022]$ ) to avoid intraoperative hypotension in the operating room. The median (IQR) time to dexmedetomidine administration following the completion of surgery was $11(10-14) \mathrm{h}$ and the mean (SD) weight-adjusted dose of intranasal dexmedetomidine was $1.29(0.24) \mu \mathrm{g} / \mathrm{kg}$.

During the 5-h observation period, dexmedetomidine decreased HR by 10.4 (3.7) beats/min (95\% CI 2.9-17.8; $p=0.004)$ and MAP by 16.2 (4.4) $\mathrm{mmHg}$ (95\% CI 7.3-25.1; $p<0.001)$. After dexmedetomidine administration, MAP was significantly lower at 1,2 , and $3 \mathrm{~h}$ ( $p \leq 0.01$ for all comparisons) and HR at $2 \mathrm{~h}$ compared with baseline values $(p=0.03)$ (Table 2, Fig. 1 and Fig. 2). $\mathrm{SpO}_{2}$ and $\mathrm{RR}$ remained unchanged from baseline during the observation period ( $p>0.20$ for all comparisons) (Table 2, Figs. 3 and 4). The decreases in HR or MAP were not associated with the weight-adjusted dexmedetomidine dose, age, or opioid consumption.
The cumulative 6-h opioid requirement was significantly reduced after dexmedetomidine administration compared with the 6-h cumulative opioid administration before dexmedetomidine (median difference $-0.24 \mathrm{mg} / \mathrm{kg}$; 95\% CI -0.63 to $0.02 ; p=0.005$ ). (Fig. 5) The decrease in opioid consumption was negatively associated with age $(p=0.01)$, but not with weight, body mass index (BMI), gender, or the weight-adjusted dexmedetomidine dose. Cumulative opioid consumption following dexmedetomidine administration was negatively associated with $\mathrm{HR}(\beta=0.596 ; p=0.02$; $\log _{\mathrm{e}}$ opioid consumption).

Patients were more sedated after dexmedetomidine dosing and mRASS decreased in all patients (median difference -2 ; 95\% CI 2-4; $p<0.001$ ) (Fig. 6). Baseline mRASS was not associated with the anesthesia method employed, duration of anesthesia, or used anesthetic. mRASS change was not associated with age, weight, height, BMI, gender, or weight-adjusted dexmedetomidine dose.

Median (IQR) time to patient mobilization after dexmedetomidine administration was $11 \mathrm{~h}(8-12)$ but was not applicable for two patients due their baseline condition.

Hypotension related to intranasal dexmedetomidine administration was observed in three patients within $3 \mathrm{~h}$ of dexmedetomidine administration. Two patients required one to two single doses of ephedrine to increase MAP > $65 \mathrm{mmHg}$. No other adverse or serious adverse events were recorded.

\section{Discussion}

This preliminary report suggests that use of intranasal dexmedetomidine is feasible for treatment of postoperative agitation and/or refractory pain in the surgical postoperative care unit. Although plenty of literature exists addressing the efficacy of dexmedetomidine for prevention of postoperative delirium in older adults $[10,11]$ and as an adjunct for multimodal analgesia $[12,13]$, use of dexmedetomidine outside the operating room or intensive care unit has not been previously studied in older adult patients. Intranasal dexmedetomidine may allow for the use of sedation outside the intensive care unit, safely, when hourly monitoring for 3 $\mathrm{h}$ following administration can be arranged.

Patients undergoing orthopedic surgery are often older and at high risk for adverse drug effects and development of postoperative delirium. Older patients are susceptible to unwanted side effects of medications due to age-related changes in pharmacokinetics and pharmacodynamics. Polypharmacy is also a common phenomenon among older adult patients, further increasing risk for adverse drug effects [14]. Age-related changes in physiology and comorbidities lead to limited compensatory mechanisms and consequently the ability to deal with possible side effects of drugs is 
Table 1 Patient characteristics

Age, mean (SD)

$79.9(7.5)$

BMI, mean (SD)

$28.1(5.2)$

Male/female, $n$

$11 / 12$

Weight-adjusted dexmedetomidine dose $(\mu \mathrm{g} / \mathrm{kg})$, mean (SD)

Time to dexmedetomidine administration from surgery (h), median (IQR)

Fraction of inspired oxygen during dexmedetomidine administration (\%), median (IQR)

Spinal anesthesia/general anesthesia, $n$

$17 / 6$

Time of surgery (min), median (IQR)

Time of anesthesia (min), median (IQR)

Patients requiring intraoperative norepinephrine, $n$

Intraoperative norepinephrine dose $(\mu \mathrm{g} / \mathrm{kg} / \mathrm{min})$, median (IQR)

Procedure performed, $n$

Total hip arthroplasty

8

Total knee arthroplasty

9

Hip fracture

3

Laminectomy

Total shoulder arthroplasty

1

Comorbidities, $n$

Hypertension

Atrial fibrillation

Hypothyreosis

Diabetes mellitus

Hypercholesterolemia

Asthma

Coronary artery disease

Alzheimer disease

$B M I$ body mass index, $I Q R$ interquartile range, $S D$ standard deviation

Table 2 Hemodynamic and respiratory parameters

\begin{tabular}{|c|c|c|c|c|c|c|}
\hline & \multirow[t]{2}{*}{ Baseline } & \multicolumn{5}{|c|}{ Time from index administration } \\
\hline & & $1 \mathrm{~h}$ & $2 \mathrm{~h}$ & $3 \mathrm{~h}$ & $4 \mathrm{~h}$ & $5 \mathrm{~h}$ \\
\hline Heart rate (bpm) & $74(14)$ & $69(12)$ & $67(12)^{*}$ & $68(12)$ & $68(11)$ & $69(10)$ \\
\hline Mean arterial pressure $(\mathrm{mmHg})$ & $90(12)$ & $75(11)^{* * *}$ & $76(13)^{* * *}$ & $79(15)^{* *}$ & $83(14)$ & $86(12)$ \\
\hline Oxygen saturation $\left(\mathrm{SpO}_{2}\right)$ & $95(3)$ & $95(2)$ & $95(3)$ & $95(2)$ & $95(3)$ & $96(2)$ \\
\hline Respiratory rate (1/min) & $14(4)$ & $15(4)$ & $16(4)$ & $15(4)$ & $15(4)$ & $15(3)$ \\
\hline
\end{tabular}

Data are shown as mean and standard deviation

$\mathrm{SpO}_{2}$ peripheral oxygen saturation

$* p<0.05, * * p<0.01, * * * p<0.001$ compared with baseline

compromised. Clearance of dexmedetomidine is not influenced by age but the sedative effect appears to be more prominent in older adults [15]. In the geriatric population, an adequate level of sedation may be achieved with lower doses of dexmedetomidine [16].

The effect of dexmedetomidine on postoperative recovery has mainly been studied using intravenous administration $[17,18]$. The intranasal route is a highly effective way to administer medications, as hepatic first pass metabolism can be bypassed, and systemic bioavailability is therefore high. Intranasal administration is often chosen on grounds of bolus dosing and easier administration compared with intravenous administration. Furthermore, intranasal administration lacks the risks of losing the administration route and needle injuries for staff, even if the patient is uncooperative. 
Fig. 1 Heart rate (beats per min) after administration of intranasal dexmedetomidine $(* p<0.05)$

Fig. 2 Mean arterial pressure after administration of intranasal dexmedetomidine $(* p<0.05)$
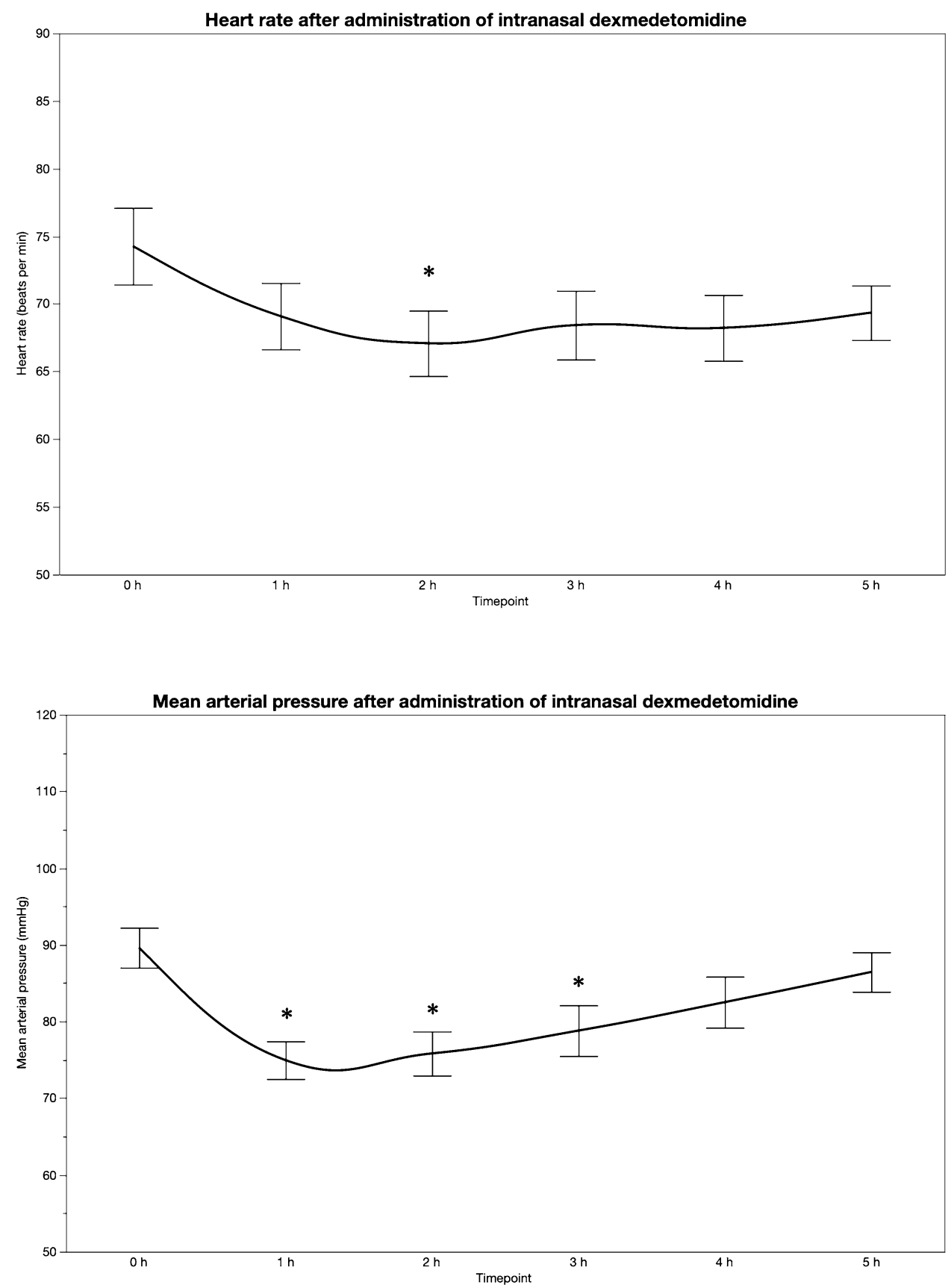

The hemodynamic effects of dexmedetomidine may be attenuated by extravascular dosing compared with intravenous administration [19]. In two studies comparing pharmacodynamic effects of intranasal and intravenous administration in healthy adult volunteers, hemodynamic effects emerged more rapidly after intravenous administration but no difference in the magnitude of MAP and HR decreases were observed between the groups $[8,20]$. A previous study suggested that even intranasal administration of dexmedetomidine might lead to detrimental hemodynamic effects in older adults [21], but contrary to our study, dexmedetomidine was administered intraoperatively together with other anesthetics. In the present study, intranasal dexmedetomidine had a slight lowering effect on both blood pressure and heart rate as expected. The maximal effect on blood pressure was observed $1-2 \mathrm{~h}$ after administration of intranasal dexmedetomidine. Two patients required one to two single doses of ephedrine for hypotension, which suggests that careful observation of hemodynamics for at least $3 \mathrm{~h}$ after administration of intranasal dexmedetomidine in geriatric patients is warranted. Weight-adjusted mean dexmedetomidine dose in our study was $1.31 \mu \mathrm{g} / \mathrm{kg}$, which is similar to intranasal dexmedetomidine dosages used in previous adult studies [7, 21]. Perhaps an even smaller amount of dexmedetomidine 
Fig. 3 Peripheral oxygen saturation $\left(\mathrm{SpO}_{2}\right)$ after administration of intranasal dexmedetomidine
Fig. 4 Respiratory rate (1/min) after administration of intranasal dexmedetomidine
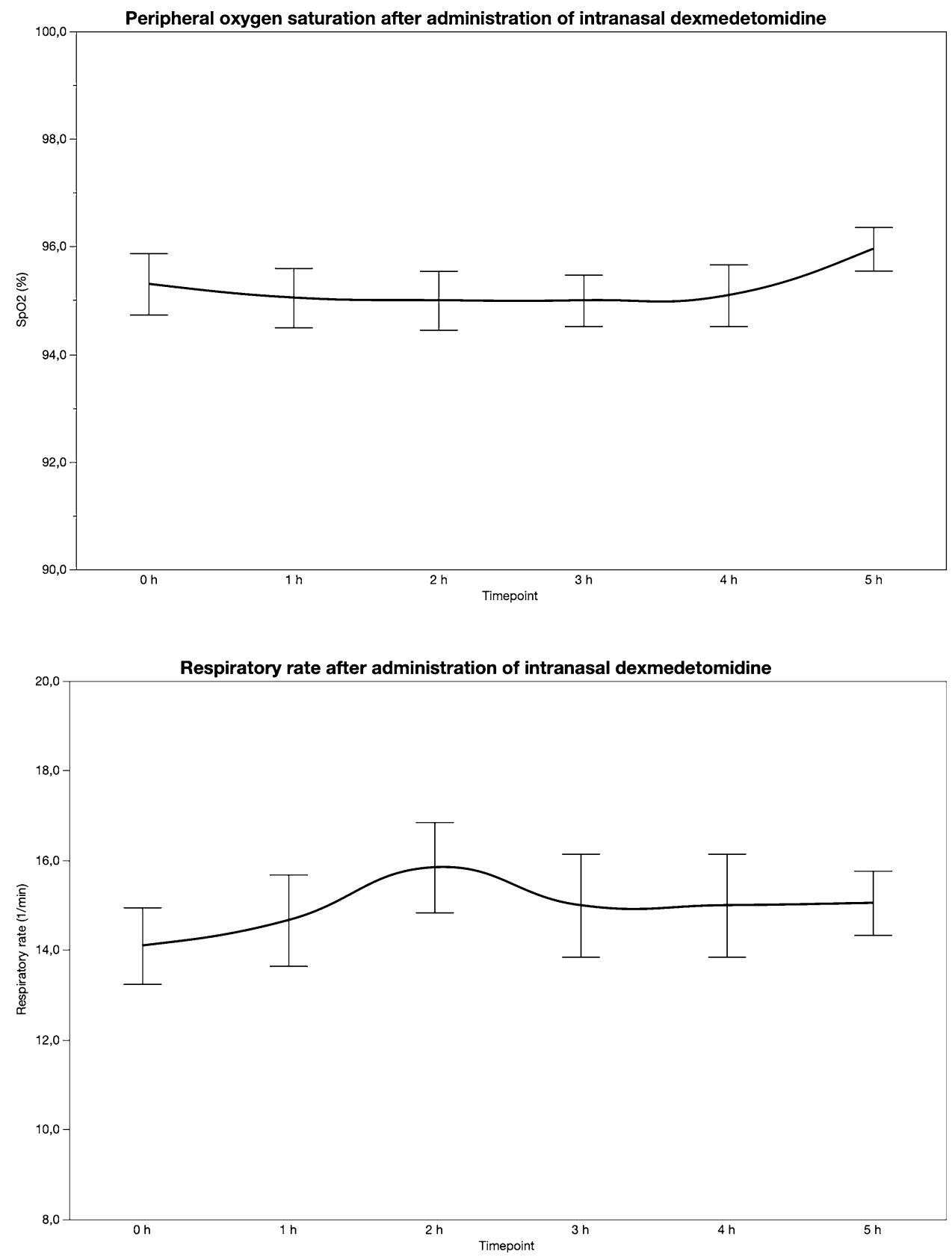

might suffice for older adults, which in turn would probably result in even less hemodynamic side effects.

The time to mobilization was relatively long compared with the sedative and hemodynamic effects of intranasal dexmedetomidine, which usually last only up to 3-4 h [8]. However, older orthopedic surgery patients are usually mobilized at the earliest on the first postoperative morning [22] and most of the patients in our study cohort received dexmedetomidine during the first postoperative night. Considering the pronounced effects that dexmedetomidine may cause in older adults, maintaining patients in a supine or semi-recumbent position at for least $5 \mathrm{~h}$ after administration of intranasal dexmedetomidine can be recommended.
Treatment of postoperative agitation and restlessness in the ward setting poses a genuine challenge for healthcare professionals. Evidence considering the efficacy of pharmacologic interventions on postoperative delirium is lacking and current guidelines primarily recommend the use of non-pharmacologic interventions [23, 24]. Pharmacological management of agitation usually includes neuroleptic agents (mainly haloperidol) and benzodiazepines. Fragile geriatric patients are more prone to haloperidol side effects such as extrapyramidal symptoms, QT-prolongation, and fatal arrythmias [25]. Use of benzodiazepines may result in memory impairment, respiratory depression, and delirium [26]. In most cases, patients cannot be constantly monitored 
Fig. 5 Cumulative opioid consumption as oral morphine equivalents $6 \mathrm{~h}$ before and $6 \mathrm{~h}$ after administration of intranasal dexmedetomidine

Fig. 6 Modified Richmond Agitation and Sedation Score (mRASS) before and after administration of intranasal dexmedetomidine

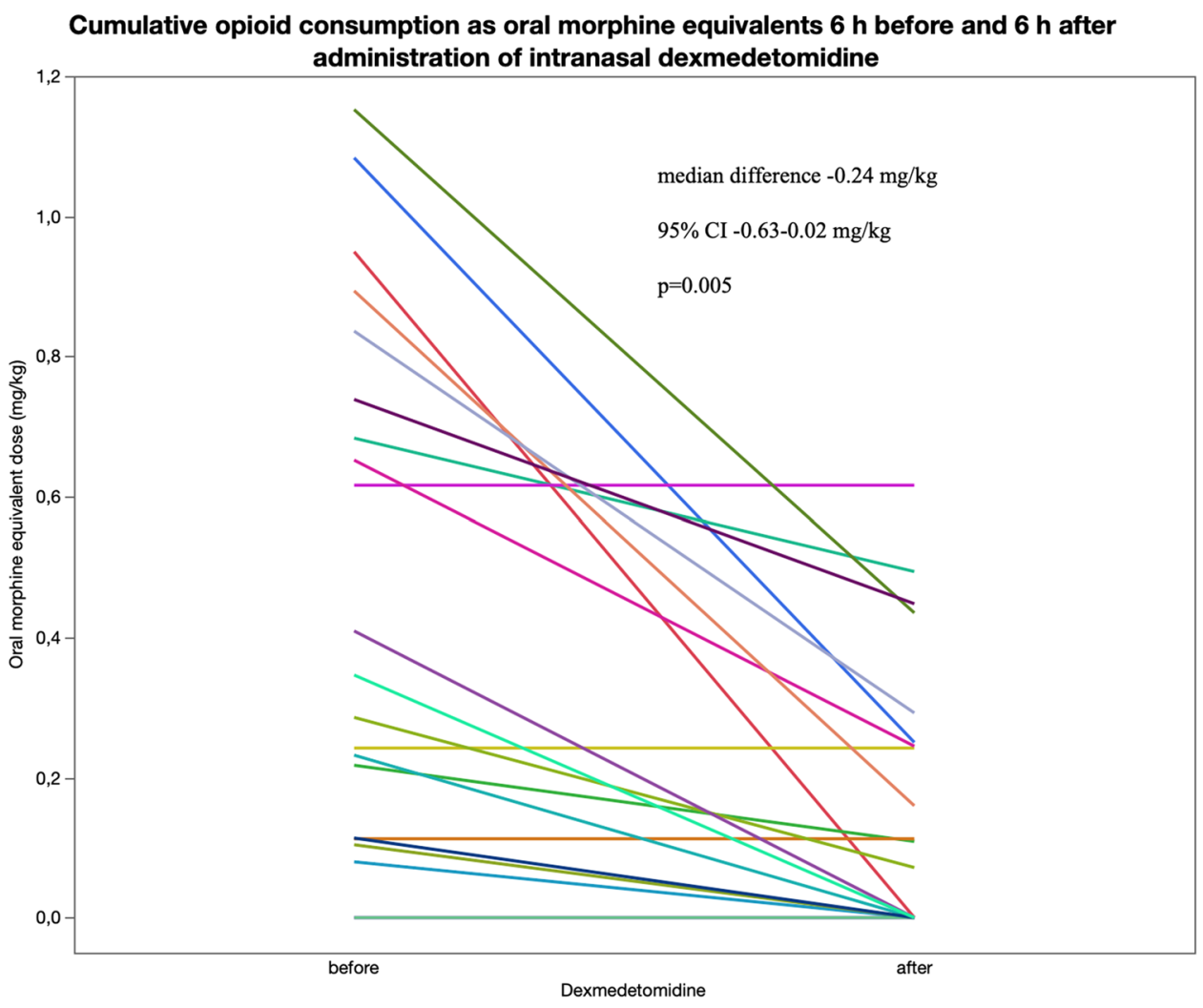

Modified Richmond Agitation and Sedation Score (mRASS) before and after administration of intranasal dexmedetomidine

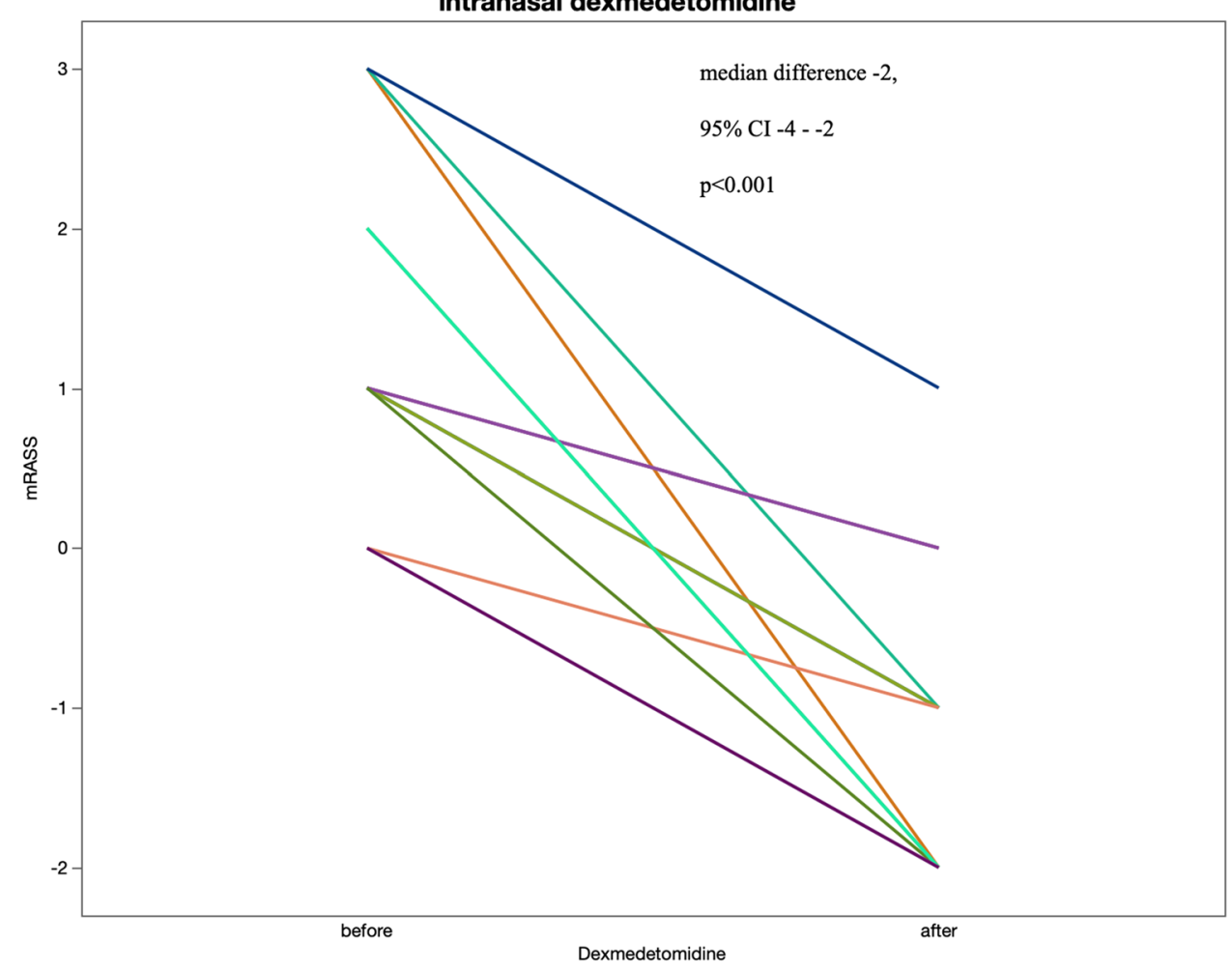


in the ward setting, which would be required for safe administration of these medications.

Compared with traditional analgosedative agents, dexmedetomidine has little effect on respiration [27, 28], and in the present study we found that $\mathrm{RR}$ and $\mathrm{SpO}_{2}$ remained unchanged after administration of intranasal dexmedetomidine. However, recent studies have shown that sedation with dexmedetomidine increases airway collapsibility and decreases hypoxic ventilatory response similarly to propofol in healthy volunteers $[29,30]$. Thus, observation of respiratory parameters is required, especially when administering dexmedetomidine to patients with obstructive sleep apnea.

Opioids have traditionally been the cornerstone of postoperative analgesia following orthopedic surgery. There is increasing concern of opioid-induced adverse effects worldwide [31], and especially in older adults these undesirable effects are pronounced. Opioids are associated with an increased risk for postoperative delirium in older adults [32], but on the other hand, postoperative pain also has a negative effect on mental status and anxiety and should therefore be prevented and treated actively [33]. When contemplating postoperative analgesic regimens for geriatric patients, caregivers must balance efficacy with the incidence of interactions and adverse effects of medications [34]. Analgesic effect of dexmedetomidine is well established and prior studies suggest that dexmedetomidine in the intranasal form has an opioid-sparing effect [7, 35]. As with prior studies, nasal dexmedetomidine reduced opioid consumption considerably in our study. Use of dexmedetomidine as part of multimodal analgesia could be particularly beneficial for geriatric patients, concurrently reducing the need for opioids and improving postoperative pain management.

Retrospective design, limited number of patients, and lack of controls are the main limitations of this study. Although we included consecutive patients receiving intranasal dexmedetomidine to avoid any selection bias, patients without hourly monitoring of vital parameters, patients with concomitant sedative medication, and patients receiving vasoactive medication prior to dexmedetomidine administration were excluded from the analyses. Another limitation was imperfect recording of pain scores, which is why we were not able to include them in the analysis. Also, postoperative delirium was not assessed using validated delirium assessment methods such as the Confusion Assessment Method for the Intensive Care Unit (CAM-ICU). Our goal was not to confirm the safety of intranasal dexmedetomidine in an older adult population, but rather to investigate the feasibility of this approach in the ward during postoperative care.

Further studies are warranted to address the safety and feasibility of intranasal dexmedetomidine use in a ward setting more precisely. A prospective study with a larger patient population is needed to confirm these preliminary findings. We suggest that additional studies examining the optimal dose of intranasal dexmedetomidine for older adult patients should be performed to find the lowest effective dose.

\section{Conclusion}

These preliminary findings suggest that intranasal dexmedetomidine has little effect on respiration and is a possible option for treatment of postoperative restlessness, agitation, and pain in geriatric patients undergoing surgery. However, hemodynamic changes related to intranasal dexmedetomidine administration need to be taken into account and observed in older adults.

Supplementary Information The online version contains supplementary material available at https://doi.org/10.1007/s40266-021-00846-6.

\section{Declarations}

Funding Open access funding provided by University of Turku (UTU) including Turku University Central Hospital. The study group did not receive any funding from external resources.

Conflicts of interest Panu Uusalo, Suvi-Maria Seppänen, and Mikko Järvisalo have no conflicts of interest that are directly relevant to the content of this article.

Ethics approval The study protocol was approved by the Turku University Clinical Research Center scientific ethics review board and the Hospital district of Southwest Finland (T266/2020).

Consent to participate For this retrospective, register-based study, the regulatory review board waived the need for informed consent in terms of data collection and analysis and publication of results.

Consent for publication For this retrospective, register-based study, the regulatory review board waived the need for informed consent in terms of data collection and analysis and publication of results.

Availability of data and material Data that supported the findings of this study are available from the data sets of the Department of Anesthesiology and Intensive Care and the Informatics Department of Turku University Hospital on reasonable request and with permission from the Turku University Clinical Research Center scientific review board and the hospital district of Southwest Finland.

Code availability Not applicable.

Authors' contributions PU, S-MS, and MJ contributed to the study conception and design. Data collection and analysis were performed by PU, S-MS, and MJ. The first draft of the manuscript was written by PU. All authors read and approved the final manuscript.

Open Access This article is licensed under a Creative Commons Attribution-NonCommercial 4.0 International License, which permits any non-commercial use, sharing, adaptation, distribution and reproduction in any medium or format, as long as you give appropriate credit to the original author(s) and the source, provide a link to the Creative Commons licence, and indicate if changes were made. The images or other third party material in this article are included in the article's Creative 
Commons licence, unless indicated otherwise in a credit line to the material. If material is not included in the article's Creative Commons licence and your intended use is not permitted by statutory regulation or exceeds the permitted use, you will need to obtain permission directly from the copyright holder. To view a copy of this licence, visit http://creativecommons.org/licenses/by-nc/4.0/.

\section{References}

1. Zhu H, Ren A, Zhou K, Chen Q, Zhang M, Liu J. Impact of dexmedetomidine infusion on postoperative acute kidney injury in elderly patients undergoing major joint replacement: a retrospective cohort study. Drug Des Dev Ther. 2020;14:4695-701. https ://doi.org/10.2147/DDDT.S278342.

2. Cai J, Chen Y, Hao X, Zhu X, Tang Y, Wang S, Zhu T. Effect of Intraoperative dexmedetomidine dose on postoperative first night sleep quality in elderly surgery patients: a retrospective study with propensity score-matched analysis. Front Med. 2020;7:528. https ://doi.org/10.3389/fmed.2020.00528.

3. Zeng H, Li Z, He J, Fu W. Dexmedetomidine for the prevention of postoperative delirium in elderly patients undergoing noncardiac surgery: a metaanalysis of randomized controlled trials. PLoS ONE. 2019;14:1-15. https://doi.org/10.1371/journal.pone.02180 88.

4. Zhang W, Wang T, Wang G, Yang M, Zhou Y, Yuan Y. Effects of Dexmedetomidine on postoperative delirium and expression of IL-1 $\beta$, IL- 6 , and TNF- $\alpha$ in elderly patients after hip fracture operation. Front Pharmacol. 2020;11:678. https://doi.org/10.3389/ fphar.2020.00678.

5. Pavone KJ, Cacchione PZ, Polomano RC, Winner L, Compton P. Evaluating the use of dexmedetomidine for the reduction of delirium: an integrative review. Heart Lung. 2018;47:591-601. https://doi.org/10.1016/j.hrtlng.2018.08.007.

6. Wu X, Hang LH, Wang H, Shao DH, Xu YG, Cui W, Chen Z. Intranasally administered adjunctive dexmedetomidine reduces perioperative anesthetic requirements in general anesthesia. Yonsei Med J. 2016;57:998-1005. https://doi.org/10.3349/ ymj.2016.57.4.998.

7. Seppänen S-M, Kuuskoski R, Mäkelä KT, Saari TI, Uusalo P. Intranasal dexmedetomidine reduces postoperative opioid requirement in patients undergoing total knee arthroplasty under general anesthesia. J Arthroplasty. 2020. https://doi.org/10.1016/j. arth.2020.09.032.

8. Iirola T, Vilo S, Manner T, Aantaa R, Lahtinen M, Scheinin M, Olkkola KT. Bioavailability of dexmedetomidine after intranasal administration. Eur J Clin Pharmacol. 2011;67:825-31. https:// doi.org/10.1007/s00228-011-1002-y.

9. Chester JG, Beth Harrington M, Rudolph JL. Serial administration of a modified Richmond Agitation and Sedation Scale for delirium screening. J Hosp Med. 2012;7:450-3. https://doi.org/10.1002/ jhm.1003.

10. Deiner S, Luo X, Lin H-M, Sessler DI, Saager L, Sieber FE, Lee HB, Sano M, Jankowski C, Bergese SD, Candiotti K, Flaherty JH, Arora H, Shander A, Rock P. Intraoperative infusion of dexmedetomidine for prevention of postoperative delirium and cognitive dysfunction in elderly patients undergoing major elective noncardiac surgery: a randomized clinical trial. JAMA Surg. 2017;152:e171505. https://doi.org/10.1001/jamasurg.2017.1505.

11. Duan X, Coburn M, Rossaint R, Sanders RD, Waesberghe JV, Kowark A. Efficacy of perioperative dexmedetomidine on postoperative delirium: systematic review and meta-analysis with trial sequential analysis of randomised controlled trials. Br J Anaesth. 2018;121:384-97. https://doi.org/10.1016/j.bja.2018.04.046.
12. Tang C, Xia Z. Dexmedetomidine in perioperative acute pain management: a non-opioid adjuvant analgesic. J Pain Res. 2017;10:1899-904. https://doi.org/10.2147/JPR.S139387.

13. Bielka K, Kuchyn I, Babych V, Martycshenko K, Inozemtsev $\mathrm{O}$. Dexmedetomidine infusion as an analgesic adjuvant during laparoscopic cholecystectomy: a randomized controlled study. BMC Anesthesiol. 2018;18:44. https://doi.org/10.1186/s1287 1-018-0508-6.

14. Atkin PA, Veitch PC, Veitch EM, Ogle SJ. The epidemiology of serious adverse drug reactions among the elderly. Drugs Aging. 1999;14:141-52. https://doi.org/10.2165/00002512-19991402000005.

15. Weerink MAS, Struys MMRF, Hannivoort LN, Barends CRM, Absalom AR, Colin P. Clinical pharmacokinetics and pharmacodynamics of dexmedetomidine. Clin Pharmacokinet. 2017;56:893-913. https://doi.org/10.1007/s40262-017-0507-7.

16. Kim J, Kim WO, Kim H-B, Kil HK. Adequate sedation with single-dose dexmedetomidine in patients undergoing transurethral resection of the prostate with spinal anaesthesia: a dose-response study by age group. BMC Anesthesiol. 2015;15:17. https://doi. org/10.1186/1471-2253-15-17.

17. Ge DJ, Qi B, Tang G, Li JY. Intraoperative dexmedetomidine promotes postoperative analgesia and recovery in patients after abdominal hysterectomy: a double-blind, randomized clinical trial. Sci Rep. 2016;6:1-7. https://doi.org/10.1038/srep21514.

18. Mei B, Meng G, Xu G, Cheng X, Chen S, Zhang Y, Zhang M, Liu $\mathrm{X}, \mathrm{Gu}$ E. Intraoperative sedation with dexmedetomidine is superior to propofol for elderly patients undergoing hip arthroplasty: a prospective randomized controlled study. Clin J Pain. 2018;34:811-7. https://doi.org/10.1097/AJP.0000000000000605.

19. Uusalo P, Al-Ramahi D, Tilli I, Aantaa RA, Scheinin M, Saari TI. Subcutaneously administered dexmedetomidine is efficiently absorbed and is associated with attenuated cardiovascular effects in healthy volunteers. Eur J Clin Pharmacol. 2018;74:1047-54. https://doi.org/10.1007/s00228-018-2461-1.

20. Li A, Yuen VM, Goulay-Dufaÿ S, Sheng Y, Standing JF, Kwok PCL, Leung MKM, Leung AS, Wong ICK, Irwin MG. Pharmacokinetic and pharmacodynamic study of intranasal and intravenous dexmedetomidine. Br J Anaesth. 2018;120:960-8. https:// doi.org/10.1016/j.bja.2017.11.100.

21. Barends CRM, Driesens MK, Struys MMRF, Visser A, Absalom AR. Intranasal dexmedetomidine in elderly subjects with or without beta blockade: a randomised double-blind single-ascendingdose cohort study. Br J Anaesth. 2020. https://doi.org/10.1016/j. bja.2019.12.025.

22. Guerra ML, Singh PJ, Taylor NF. Early mobilization of patients who have had a hip or knee joint replacement reduces length of stay in hospital: a systematic review. Clin Rehabil. 2015;29(9):844-54. https://doi.org/10.1177/0269215514558641.

23. Aldecoa C, Bettelli G, Bilotta F, Sanders RD, Audisio R, Borozdina A, Cherubini A, Jones C, Kehlet H, MacLullich A, Radtke F, Riese F, Slooter AJC, Veyckemans F, Kramer S, Neuner B, Weiss B, Spies CD. European Society of Anaesthesiology evidence-based and consensus-based guideline on postoperative delirium. Eur J Anaesthesiol. 2017;34:192-214. https://doi. org/10.1097/EJA.0000000000000594.

24. American Geriatrics Society. Abstracted clinical practice guideline for postoperative delirium in older adults. J Am Geriatr Soc. 2015;63:142-50. https://doi.org/10.1111/jgs.13281.

25. Yoon H-J, Park K-M, Choi W-J, Choi S-H, Park J-Y, Kim J-J, Seok J-H. Efficacy and safety of haloperidol versus atypical antipsychotic medications in the treatment of delirium. BMC Psychiatry. 2013;13:240. https://doi.org/10.1186/1471-244X-13-240.

26. Madhusoodanan S, Bogunovic OJ. Safety of benzodiazepines in the geriatric population. Expert Opin Drug Saf. 2004;3:485-93. https://doi.org/10.1517/14740338.3.5.485. 
27 Belleville JP, Ward DS, Bloor BC, Maze M. Effects of intravenous dexmedetomidine in humans: I. Sedation, ventilation, and metabolic rate. Anesthesiology. 1992;77:1125-33. https://doi. org/10.1097/00000542-199212000-00013.

28 Ebert TJ, Hall JE, Barney JA, Uhrich TD, Colinco MD. The effects of increasing plasma concentrations of dexmedetomidine in humans. Anesthesiology. 2000;93(2):382-94. https://doi. org/10.1097/00000542-200008000-00016.

29. Lodenius Å, Ebberyd A, Cedborg AH, Hagel E, Mkrtchian S, Christensson E, Ullman J, Scheinin M, Eriksson LI, Fagerlund MJ. Sedation with dexmedetomidine or propofol impairs hypoxic control of breathing in healthy male volunteers: a nonblinded randomized crossover study. Anesthesiology. 2019;125(4):700-15. https://doi.org/10.1097/ALN.0000000000001236.

30. Lodenius A, Maddison KJ, Lawther BK, Scheinin M, Eriksson LI, Eastwood PR, Hillman DR, Fagerlund MJ, Walsh JH. Upper airway collapsibility during dexmedetomidine and propofol sedation in healthy volunteers: a nonblinded randomized crossover study. Anesthesiology. 2019;131(5):962-73. https://doi.org/10.1097/ ALN.0000000000002883.

31. Degenhardt L, Charlson F, Mathers B, Hall WD, Flaxman AD, Johns N, Vos T. The global epidemiology and burden of opioid dependence: results from the global burden of disease 2010 study. Addiction. 2014;109:1320-33. https://doi.org/10.1111/add.12551.

32. Brouquet A, Cudennec T, Benoist S, Moulias S, Beauchet A, Penna C, Teillet L, Nordlinger B. Impaired mobility, ASA status and administration of tramadol are risk factors for postoperative delirium in patients aged 75 years or more after major abdominal surgery. Ann Surg. 2010;251:759-65. https://doi.org/10.1097/ SLA.0b013e3181c1cfc9.

33. Lynch EP, Lazor MA, Gellis JE, Orav J, Goldman L, Marcantonio ER. The impact of postoperative pain on the development of postoperative delirium. Anesth Analg. 1998;86:781-5. https://doi. org/10.1097/00000539-199804000-00019.

34. Falzone E, Hoffmann C, Keita H. Postoperative analgesia in elderly patients. Drugs Aging. 2013;30:81-90. https://doi. org/10.1007/s40266-012-0047-7.

35. Uusalo P, Jätinvuori H, Löyttyniemi E, Kosola J, Saari TI. Intranasal Low-dose dexmedetomidine reduces postoperative opioid requirement in patients undergoing hip arthroplasty under general anesthesia. J Arthroplasty. 2019;34:686-692.e2. https://doi. org/10.1016/j.arth.2018.12.036. 